\title{
Gender and endangered languages: Intersections
}

\author{
Jocelyn Ahlers
}

While studies of the interplay of language use and gendered identity have pointed to the complex interactions between the two, and while researchers have similarly considered the ways in which endangered languages of heritage serve as resources in the construction of identity in communities focused on language revitalization, the intersection of these two fields of study has only rarely been examined. As awareness of the endangered status of many of the world's languages has grown, the processes by which languages become restricted within their communities of use, and the roles that community members can and do play in reversing that restriction, have been studied and theorized by scholars within the fields of linguistics and anthropology. This collection of papers builds upon and expands the scope of such research by looking at the role that gender plays in both language maintenance and language revitalization processes within communities whose languages are endangered. These papers also explore the impact that language endangerment and revitalization have on the construction of gender, and, indeed, upon the gendered identities available to community members. Through the exploration of processes particular to individual communities, these papers offer a more general understanding of the complex interplay of gendered identity, language use, ideology, and community, thus expanding our understanding of the ways in which gender and language interact, not only in endangered language communities, but more broadly.

\footnotetext{
Affiliation

California State University, San Marcos, USA

email: jahlers@csucsm.edu
} 
This collection of papers begins with Wertheim's analysis of the gendered differences in politeness behaviors among Tatar language activists. Tatar nationalist men privilege their nationalist identity over communicative efficacy to a far greater degree than Tatar women, and they are far more willing to violate politeness norms in the process. Adkins and Davis' paper takes up the construction of gender and sexual hegemony in the context of Breton language revitalization through their consideration of Ken Tuch, a web-based Breton language video series. The links between Breton dialects and normative and non-normative female gender roles point to some of the ways in which projects of language revitalization can both reinforce traditional gender roles and create space for the exploration of new gendered identities. Ahlers' consideration of gendered identity in Native California communities focuses on the socialization of girls and young women into multiple communities of practice within the context of heritage language endangerment and revitalization, and on the simultaneous acquisition of ideologies associated with those gendered identities. This has implications for girls' and young women's understanding and deployment of linguistic features such as silence in the performance of gendered identity. Leonard takes up a very similar issue in his consideration of Miami language reclamation. His article is written from the insider's perspective, and takes up an examination of some of the ways in which projects of language revitalization can emphasize essentialist notions of identity, with a focus on implications for the range of gendered identities available to community members. Finally, Cavanaugh's commentary highlights the themes which arise across these articles as they look at very different communities.

I would particularly like to thank Madeleine Adkins for her partnership in proposing and developing this Special Issue, and the editors of Gender and Language for their interest and support in its publication. I would also like to express my gratitude to Jillian Cavanaugh, both for her insightful commentary on the papers in this collection, and for her aid in the preparation of the Special Issue. Finally, I am deeply appreciative of the anonymous reviewers of each of these papers for their careful and considered comments and suggestions. 